\title{
Leaf reflectance can surrogate foliar economics better than physiological traits across macrophyte species
}

\author{
Paolo Villa ${ }^{1 *} \mathbb{D}$, Rossano Bolpagni ${ }^{1,2}$, Monica Pinardi $^{1}$ and Viktor R. Tóth ${ }^{3^{*}}$
}

\begin{abstract}
Background: Macrophytes are key players in aquatic ecosystems diversity, but knowledge on variability of their functional traits, among and within species, is still limited. Remote sensing is a high-throughput, feasible option for characterizing plant traits at different scales, provided that reliable spectroscopy models are calibrated with congruous empirical data, but existing applications are biased towards terrestrial plants. We sampled leaves from six floating and emergent macrophyte species common in temperate areas, covering different phenological stages, seasons, and environmental conditions, and measured leaf reflectance $(400-2500 \mathrm{~nm}$ ) and leaf traits (dealing with photophysiology, pigments, and structure). We explored optimal spectral band combinations and established non-parametric reflectance-based models for selected traits, eventually showing how airborne hyperspectral data could capture spatial-temporal macrophyte variability.

Results: Our key finding is that structural—leaf dry matter content, leaf mass per area_-and biochemical—chlorophyll-a content and chlorophylls to carotenoids ratio-traits can be surrogated by leaf reflectance with normalized error under $17 \%$ across macrophyte species. On the other hand, the performance of reflectance-based models for photophysiological traits substantively varies, depending on macrophyte species and target parameters.

Conclusions: Our main results show the link between leaf reflectance and leaf economics (structure and biochemistry) for aquatic plants, thus envisioning a crucial role for remote sensing in enhancing the level of detail of macrophyte functional diversity analysis to intra-site and intra-species scales. At the same time, we highlighted some difficulties in establishing a general link between reflectance and photosynthetic performance under high environmental heterogeneity, potentially opening further investigation directions.
\end{abstract}

Keywords: Aquatic plants, Functional traits, Intraspecific variability, Leaf economics spectrum (LES), Remote sensing, Spectroscopy

\section{Background}

At the borders of land and water, incorporating both aquatic and terrestrial features, wetlands are among the most important [1, 2], most productive [3] and most

\footnotetext{
*Correspondence: villa.p@irea.cnr.it; toth.viktor@blki.hu

${ }^{1}$ Institute for Electromagnetic Sensing of the Environment, National

Research Council of Italy (CNR-IREA), Milan, Italy

${ }^{3}$ Balaton Limnological Research Institute, Tihany, Hungary

Full list of author information is available at the end of the article
}

diverse [4] ecosystems in temperate areas. The origin of this diversity is attributed both to their transitional status [5] and to the high spatial and temporal variability of environmental conditions [6]. Macrovegetation of these areas is acclimated to the seasonal and spatial changes of their habitat, created along the major environmental gradient transition from one ecotype to another in monospecific stands, and coenoclines in mixed stands $[7,8]$. Aquatic plants are key ecosystem players in littoral ecotones, as they are hotspots of biogeochemical cycling, original author(s) and the source, provide a link to the Creative Commons licence, and indicate if changes were made. The images or other third party material in this article are included in the article's Creative Commons licence, unless indicated otherwise in a credit line to the material. If material is not included in the article's Creative Commons licence and your intended use is not permitted by statutory regulation or exceeds the permitted use, you will need to obtain permission directly from the copyright holder. To view a copy of this licence, visit http://creativecommons.org/licenses/by/4.0/. The Creative Commons Public Domain Dedication waiver (http://creativeco mmons.org/publicdomain/zero/1.0/) applies to the data made available in this article, unless otherwise stated in a credit line to the data. 
actively impact the ecosystem by regulating water flow and sedimentation, and promote biodiversity by attracting and sheltering a large number of species ([9-12]. At the same time, wetlands diversity and functioning are dramatically impacted by alien plants invasions [13].

Environmental heterogeneity, in joint action with genetic variability and morpho-functional plasticity of macrophyte species, result in faceted phenotypic and phenological adaptations and/or acclimations within the local populations, shaping communities and even individuals [7, 14-19]. Multi-dimensional trait variability is a recent object of investigation in functional ecology [20-22]. Knowledge about ranges and interconnections of trait variability within aquatic plant communities (populations) is still relatively limited, probably due to the peculiar features of macrophytes and the environmental patchiness of their habitat [8]. The issue of disentangling the effects of inter-specific and intra-specific trait variability is at the centre of the current debate [2325], especially for key traits related to the leaf economics spectrum (LES, [26]). Moreover, investigating spatial patterns of trait variability at local scales is a relatively recent topic [27-30] and some light has still to be shed on this level of heterogeneity in plant communities, with implications on productivity and connected processes [31].

Exploring this fine-scale variability with direct measurements, usually carried out in situ and in the laboratory, is very time and resource consuming, and often logistically constrained in aquatic systems. The level of maturity in platforms and techniques achieved by remote sensing (RS) make it a feasible and potentially very effective way forward in characterizing selected plant trait variability within communities at different geographic scales [32-34], overcoming logistic and economic constraints.

In particular, the last two decades have seen the development of a range of applications for RS of plant biophysical and bio-chemical traits, with an intensification of this trend in the last decade [35-37]. RS-based works have by a large majority focused on terrestrial plants, from forest and grassland biomes (e.g. [32, 38-43], but some developments on wetland and aquatic vegetation have been recently documented [44-46]. As aquatic plants feature significant differences with respect to terrestrial ones in terms of morphology and physiology ([47-49], the relations between leaf optical properties and reflectance at the basis of functional traits modelling of terrestrial vegetation, such as the ones embedded into PROSPECT models [50], cannot be taken by granted, and to our best knowledge, a systematic check of those relations in current literature is still lacking. For being effective, applications of RS for mapping plant functional traits require an analysis of which traits can be modelled from spectral reflectance, and this is preferably done using data covering natural trait heterogeneity. Empirical approaches for assessing reflectance spectra as a proxy of plant traits, at leaf or canopy level, normally employ spectroscopy-based methods ranging from parametric regression models input with spectral indices, computed as band combinations (e.g. [51-53]) to non-parametric regression models, such as partial least-square regression (e.g. $[38,54-56])$.

Towards meaningful applications of RS for plant functional ecology, the fundamental question is: which leaf traits, within a specific plant group, can be reliably modelled (and which others cannot) using spectroscopy? With this study, we aim to provide an answer to this question - which has been already explored over a range of terrestrial species-for what concerns floating and emergent aquatic plants common in temperate areas. To tackle this question, we purposely collected empirical data of leaf spectra and a set of leaf traits-dealing with photophysiology, pigments and leaf structure-from six macrophyte species under different times, seasons and environmental conditions, over three sites located in Europe.

The objectives of this work are: (i) to assess the variability in leaf functional traits within and among macrophyte species, with attention to alien vs. native taxa dualism; (ii) to evaluate which functional traits-photophysiological, biochemical and structural-can be effectively modelled across macrophyte species using leaf reflectance, and which wavelength ranges and combinations are more sensitive to specific traits; and (iii) to test how spectral proxies for selected traits can be exploited using remote sensing data for the straightforward visualization of spatial and temporal functional variability of macrophyte communities, at inter- and intra-species level.

\section{Methods}

\section{Sampling site descriptions}

Macrophyte samples were collected from three temperate shallow lakes surrounded by wetlands and hosting abundant macrophyte communities, located in central and southern Europe: Lake Hídvégi (Hungary), Mantua lakes system (Italy), and Lake Varese (Italy).

Lake Hídvégi, located in western Hungary $\left(46^{\circ} 38^{\prime} \mathrm{N}\right.$, $17^{\circ} 08^{\prime} \mathrm{E} ; 110 \mathrm{~m}$ a.s.l.), is an artificial lake system built in 1985 as a part of the Kis-Balaton Water Protection System, that has the overall function of retaining inorganic nutrients and total suspended solids carried by the Zala River into Lake Balaton [57]. Lake Hídvégi is a shallow, eutrophic to hypertrophic, predominantly open-water habitat (area: $18 \mathrm{~km}^{2}$, average depth: $1.1 \mathrm{~m}$ ) partly covered by floating macrophytes, with Trapa natans L. as dominant species and some presence of Nuphar lutea 
(L.) Sm. and Nymphaea alba L. [46, 58]. Helophyte communities in the littoral zone are composed of reed beds (Phragmites australis (Cav.) Trin. ex Steud.) and cattail beds (Typha spp.).

Mantua lakes system, located in northern Italy plain $\left(45^{\circ} 10^{\prime} \mathrm{N}, 10^{\circ} 47^{\prime} \mathrm{E} ; 15 \mathrm{~m}\right.$ a.s.l.), is composed of three dimictic shallow fluvial-lakes (area: $6.1 \mathrm{~km}^{2}$; average depth: $3.5 \mathrm{~m}$ ), with two connected wetlands (upstream and downstream of lakes). The Superior, Middle and Inferior lakes are characterized by high turbidity and eutrophic conditions, and the water level is kept fixed to prevent flooding the city of Mantua. Macrophyte communities in the system are populated by both native ( $T$. natans, N. lutea, N. alba in open water areas, and P. australis in wetlands) and alien species [46, 59, 60]: Nelumbo nucifera Gaertn., introduced into the lake around a century ago, and Ludwigia hexapetala (Hook. \& Arn.) Zardini, H.Y. Gu \& P.H. Raven, which started spreading here during the last decade.

Lake Varese, located in subalpine northern Italy $\left(45^{\circ}\right.$ $49^{\prime} \mathrm{N}, 8^{\circ} 44^{\prime} \mathrm{E}$; $238 \mathrm{~m}$ a.s.l.), is a monomictic, eutrophic lake (area: $14.2 \mathrm{~km}^{2}$; average depth: $10.9 \mathrm{~m}$ ) subject to high anthropic pressures and nutrient loads. The southern shores of the lake host extensive stands of floating macrophytes, mainly T. natans and N. lutea, with some presence of $N$. alba [61]. Some tracts of the littoral zone have been colonized in the last couple of decades by alien species, $N$. nucifera and L. hexapetala.

\section{Field measurements}

Boat-based surveys were carried out in the three sites for 3 years (2016-2018), covering different times within the macrophyte growing season, spanning from late May to late July. Due to logistic and technical constraints, macrophyte beds sampled were not always the same ones in different years. During the surveys, leaf samples from six species (L. hexapetala, $N$. nucifera, $N$. alba, N. lutea. P. australis, T. natans) were measured and collected over various locations, to incorporate intra-site variability. Besides being among the most represented floating and emergent macrophytes in temperate Europe, the mentioned species show a clear dominance in the study sites, covering a vast majority (more than 90\%) of the area occupied by aquatic and wetland vegetation. A summary of sampling locations for each species and date of survey is provided in Additional file 1: Table S1. Leaf samples, either floating or emergent above water, were collected from plants growing in dense (canopy fraction cover $>60 \%$ ) and homogeneous stands, within $3 \mathrm{~m}$ of the water edge; from each plant sampled, the youngest, mature leaf, directly exposed to sunlight was taken for measurements.

\section{Leaf spectral reflectance}

Leaf reflectance in the visible to shortwave infrared range $(350-2500 \mathrm{~nm}$, with a spectral resolution of $3 \mathrm{~nm}$ for wavelengths under $1000 \mathrm{~nm}$, and $<8 \mathrm{~nm}$ up to 2500) was measured using a portable full range spectroradiometer (SR-3500, Spectral Evolution, Lawrence, USA), following the protocol described in Tóth et al. [60]. After 20-min dark adaptation, leaves were laid on a flat neoprene plate (reflectance factor $<5 \%$ ) to minimize background reflection of light transmitted through the leaves. Leaf reflected radiance was measured at contact using a probe equipped with a $5-\mathrm{W}$ internal light source under near-steady state conditions, i.e. $60 \mathrm{~s}$ after removing the leaf clip. Each spectrum is the result of 10 averaged scans, and automatic integration time optimization was used, with a maximum allowed of $50 \mathrm{~ms}$ per scan. Leaf spectra were eventually calibrated to reflectance using reflected radiance from a Spectralon panel (Labsphere, North Sutton, USA; reflectance factor $>99 \%$ for wavelengths under $1500 \mathrm{~nm}$, and $>95 \%$ up to $2500 \mathrm{~nm}$ ) as reference.

\section{Leaf photophysiology}

Photophysiological traits of macrophytes were assessed using chlorophyll fluorescence measured with a PAM2500 chlorophyll fluorometer (Heinz Walz GmbH, Germany) over the same leaves sampled for spectral reflectance measurements. Data were collected occasionally between 09:00 and 15:00, standard solar time. Relevant fluorescence yield data (initial fluorescence yield $-F_{0}$, maximal fluorescence yield $-F_{m}$ ) were measured following the protocol described in Tóth et al. [60] on mature, healthy-looking leaves after a dark-adapting period of $20 \mathrm{~min}$ with a pulse of a saturated light $(630 \mathrm{~nm}$, intensity $3000 \mu \mathrm{mol} \mathrm{m}^{-2} \mathrm{~s}^{-1}$ ). Photochemical PSII efficiency $\left(\mathrm{F}_{\mathrm{v}} / \mathrm{F}_{\mathrm{m}}\right)$, coefficient of photochemical quenching $(\mathrm{qP})$, coefficient of non-photochemical quenching (qN), maximum electron transport rate of the photosystem II (PSII) $\left(E T R_{\max }\right)$, theoretical saturation light intensity $\left(\mathrm{I}_{\mathrm{k}}\right.$, and maximum quantum yield for whole chain electron transport ( $\alpha$ were calculated using fluorescence yield data and a light response curve-with ETR measured as a function of photosynthetically active radiation (PAR; 11 steps between 5 and $787 \mu \mathrm{mol} \mathrm{m}{ }^{-2} \mathrm{~s}^{-1}$ ) - described by an exponentially saturating equation [62]. Leaf absorbance was set at 0.84 for the calculation of ETR for all the species sampled.

\section{Leaf biochemical and structural traits}

Leaf pigments, as biochemical traits directly connected with photosynthetic apparatus, and leaf structural traits were measured on our samples to represent foliar economics expressing the inner trade-off between resource 
availability and structural investments, which lies at the core of the LES.

Two leaf discs $(0.6 \mathrm{~cm}$ in diameter) were cut with a cork borer from each fresh leaf, in the vicinity of where chlorophyll fluorescence was measured. Disks were stored in aluminium foil at $<0{ }^{\circ} \mathrm{C}$ in a camping fridge until they were transferred to the laboratory, i.e. within maximum of $4 \mathrm{~h}$.

Half of the discs sampled were stored at $-20{ }^{\circ} \mathrm{C}$ in a freezer, to be used for pigments extraction, following the protocol described in Tóth et al. [60]. Upon extraction, they were homogenised in liquid $\mathrm{N}_{2}$ in a grinder, subsequently extracted in acetone solution (80\%), and stored in a fridge overnight. The extracts were centrifuged and the supernatant collected and stored at $-20{ }^{\circ} \mathrm{C}$. The full spectra of absorbance of the extracts were measured between 400 and $750 \mathrm{~nm}$ using a spectrophotometer (Shimadzu UV-2401PC, dual-beam), at $1 \mathrm{~nm}$ resolution. Finally, pigment concentrations, i.e. chlorophyll-a (Chla), chlorophyll-b (Chl-b), and total carotenoids (Car) were calculated using empirical formulae [63] and reported on a leaf area basis $\left(\mu \mathrm{g} \mathrm{cm}^{-2}\right)$. Pigment ratios were then calculated, as Chl-a to Chl-b ratio $(\mathrm{Ca} / \mathrm{Cb})$ and total chlorophylls $(\mathrm{Chl}-\mathrm{a}+\mathrm{Chl}-\mathrm{b})$ to total carotenoids ratio (Chl/Car).

The other half of leaf discs were weighted with a precision balance (Mettler Toledo AB104, 0.0001 g accuracy) to measure their fresh weight, and were then dried in a ventilated oven at $70{ }^{\circ} \mathrm{C}$ for $48 \mathrm{~h}$, after which the dry weight was measured using the same balance. From these data, dry matter content (DMC) and leaf mass per area (LMA) of each disc were calculated as the ratio of dry weight to fresh weight $\left(\mathrm{g} \mathrm{g}^{-1}\right)$, and the ratio of dry weight to disc area $\left(\mathrm{g} \mathrm{m}^{-2}\right)$ respectively.

\section{Interspecific and intraspecific variability}

Due to the non-normality of samples for some traits (and species) in our dataset, the variability of leaf traits across species was tested using non-parametric Kruskal-Wallis One Way ANOVA, and pairwise comparisons were performed using post-hoc Dunn's test, with p-value adjustment computed according to Benjamini-Hochberg method. Intraspecific variability of selected traits was assessed by calculating the coefficient of variation $(\mathrm{CV})$ of each trait for every species, using only leaf samples collected at peak of growth (mid-late July) to reduce differences due to phenology.

\section{Spectral indices and leaf traits}

For each possible combination of two spectral reflectance bands measured as described in "Leaf spectral reflectance" section within the range 400-2500 nm (987 bands), the normalized difference spectral index (NDSI) was calculated using a custom-made R script [45]. NDSIs are frequently used in RS because they offer the advantage of summarizing spectra information, while reducing uncertainty due to sensor differences and atmospheric effects and bias due to differences in vegetation background [64-66], and are defined as:

$$
N D S I_{i, j}=\frac{\rho_{i}-\rho_{j}}{\rho_{i}+\rho_{j}}
$$

where $\rho$ is leaf reflectance measured at spectral bands $i$ or $j$.

Using the same R script, the correlation (Pearson's $r$ ) between each leaf parameter, i.e. photophysiology, pigments and structural trait, and every calculated NDSIs was calculated together with the corresponding p-value (p), accounting for multiple comparisons using p-adjustment based on Bonferroni method. Even if deviations from normality were observed for some traits in our dataset (see Additional file 1: Fig. S9), we opted for the use of squared Pearson's $r$ as a measure of effect in assessing the strength of NSDI-trait relations commonly found in related literature for the easy interpretability (starting from [67]), after some tests comparing this approach with alternative ones, i.e. traits transformation or non-parametric correlations, that showed its conservativeness in assessing the strength of NDSI-trait relations, while not changing substantially the selection of the optimal band combinations (Additional file 1: Figs. S2, S3). Correlation plots featuring the coefficient of determination $\left(\mathrm{R}_{\mathrm{cal}}{ }^{2}\right)$, calculated as the square of $r$, between each leaf parameter and the complete combinations of NDSIs derived from leaf reflectance were drawn for significant relations $\left(\mathrm{p}_{\mathrm{adj}}<0.01\right)$, in order to highlight optimal two-band combinations proxies of investigated leaf photophysiology $(\alpha$, ETR $\left._{\text {max }}, \mathrm{I}_{\mathrm{k}}, \mathrm{F}_{\mathrm{v}} / \mathrm{F}_{\mathrm{m}}, \mathrm{qN}, \mathrm{qP}\right)$, pigments pool (Chl-a, Chl-b, $\mathrm{Car}, \mathrm{Ca} / \mathrm{Cb}, \mathrm{Chl} / \mathrm{Car}$ ), and structural traits (DMC, LMA).

\section{Hyperspectral modelling of leaf traits}

Partial least-square regression (PLSR) modelling [68] was used to further explore the relations between leaf reflectance and selected leaf traits across floating and emergent macrophyte species, using package $p l s$ 2.7, implemented in $\mathrm{R}([69,70]$. PLSR is a powerful tool for modelling vegetation parameters using spectral datasets because it is suitable for cases when the number of predictors is larger than that of observations and can handle multi-collinearity in predictor variables, as frequently happens with narrow-band hyperspectral data $[55,71]$.

In order to focus on meaningful relations, PLSR models were calibrated only for leaf traits that showed a minimum sensitivity to spectral reflectance, that is scoring a $\mathrm{R}_{\text {cal }}{ }^{2}$ against all combinations of NDSIs higher than 0.15 $\left(\mathrm{p}_{\mathrm{adj}}<0.01\right)$, while simultaneously excluding mutually 
correlated traits (i.e. scoring Pearson's $r$ vs. any other trait $<-0.5$, or $>0.5$ ). The number of PLSR components used for each calibrated model (with 30 components set as maximum, following preliminary tests) was optimized through minimization of the root mean square error of prediction (RMSEP) via leave-one-out cross-validation (LooCV). The best model for each trait was eventually selected by setting the number of PLSR components corresponding to minimum cross-validation RMSEP, and model performance was assessed comparing measured with PLSR predicted trait values through the coefficient of determination of measured vs. predicted traits via LooCV $\left(\mathrm{R}_{\mathrm{CV}}{ }^{2}\right)$ and the RMSE normalized based on the range of values for each trait (nRMSE). The relative importance of different wavelengths and spectral ranges to PLSR models calibrated for each variable was assessed by computing the Variable Importance of Projection (VIP; [42]).

\section{Airborne hyperspectral images}

Airborne hyperspectral images of Lake Hídvégi and Mantua lakes system were acquired from the APEX imaging spectrometer [72] on 19 July 2014 (around 12:00 local time) and 27 September 2014 (around 13:45 local time), respectively. Visible to near-infrared range APEX data were processed, resulting in hyperspectral images composed of 98 spectral bands (425-905 nm), with 3-10 nm spectral resolution.

APEX data were calibrated to at-sensor radiance units and georeferenced based on the sensor's GPS/IMU at $5 \mathrm{~m}$ spatial resolution on the ground. Surface reflectance was finally derived by applying atmospheric correction based on MODTRAN-4 code and optimized for water targets [73]. To diminish distortions due to canopy structure effects and the influence of mixture with canopy background in APEX-derived spectra, we used the vector normalization method developed by Feilhauer et al. [55] and we filtered results using previously derived spatialized information about LAI of macrophyte communities in the same sites [46], by excluding all pixels with $\mathrm{LAI}<0.67$ $\mathrm{m}^{2} \mathrm{~m}^{-2}$.

As a proof of concept for demonstrating the potential of hyperspectral remote sensing data in highlighting spatial patterns of macrophyte traits at fine scale, we have produced bio-visualisation maps as RGB composites of spectral proxies derived from APEX normalized surface reflectance bands, by calculating the NDSIs recognized as linked to selected traits from leaf spectroscopy-based analysis whose NDSI-trait relation scored an $\mathrm{R}_{\text {cal }}{ }^{2}>0.4$ within the spectral range covered by APEX.

\section{Results}

\section{Variability of macrophyte leaf traits}

Regarding traits related to photosynthetic performance, alien species showed significant differences with native ones, i.e. $N$. nucifera scored high $\alpha$ (adjusted $\mathrm{p}<0.01$ from all pairwise post-hoc Dunn's tests; Additional file 1: Fig. S1), and $L$. hexapetala scored high ETR $\mathrm{max}_{\max }, \mathrm{I}_{\mathrm{k}}$ and qP (adjusted $\mathrm{p}<0.001$ from all pairwise post-hoc Dunn's tests; Additional file 1: Fig. S1). Moreover, regulated thermal dissipation of excess absorbed light (qN) was found to be slightly lower in N. nucifera and L. hexapetala, as well as in T. natans, compared to nymphaeids ( $N$. lutea and N. alba) and P. australis (Fig. 1; Additional file 1: Fig. S1). P. australis showed quantum efficiency of photosystem II $\left(\mathrm{F}_{\mathrm{v}} / \mathrm{F}_{\mathrm{m}}\right)$ slightly higher than all other species, except $N$. alba $(\mathrm{p}<0.05$ from pairwise post-hoc Dunn's tests; Additional file 1: Fig. S1).

Ludwigia hexapetala displayed Chl-a values slightly higher than native species $(\mathrm{p}<0.05$ from all pairwise post-hoc Dunn's tests; Additional file 1: Fig. S1), while no significant difference across species was observed for Chl-b, and the lowest carotenoid content was found in $N$. nucifera and T. natans ( $\mathrm{p}<0.05$ from all pairwise posthoc Dunn's tests; Additional file 1: Fig. S1). Nymphaeids got the lowest $\mathrm{Ca} / \mathrm{Cb}$ ratio among species $(\mathrm{p}<0.05$ from pairwise post-hoc Dunn's tests), with $L$. hexapetala and $T$. natans occupying the high band of scores (Additional file 1: Fig. S1). A strong level of segmentation at species level was shown for $\mathrm{Chl} / \mathrm{Car}$ ratio $(\mathrm{p}<0.001$, KruskalWallis One Way ANOVA): $N$. nucifera and T. natans exhibited the highest scores $(\mathrm{p}<0.001$ from pairwise post-hoc Dunn's tests) and L. hexapetala, N. lutea, $N$. alba followed in decreasing Chl/Car (Additional file 1: Fig. S1).

Compared to native species, leaf DMC was higher $(\mathrm{p}<0.001$ from all pairwise post-hoc Dunn's tests) and LMA lower ( $\mathrm{p}<0.001$ from all pairwise post-hoc Dunn's tests) for both $L$. hexapetala and $N$. nucifera (Fig. 1; Additional file 1: Fig. S1). Inter-species DMC patterns tend to be similar to those of $\mathrm{Chl} / \mathrm{Car}$, with the exception of T. natans, and strong differentiation in LMA was observed among species, with nymphaeids scoring the highest values and $T$. natans spanning the widest range (Fig. 1; Additional file 1: Fig. S1).

Leaf data collected at peak of growth (i.e. samples collected in July) exhibited a notable degree of intraspecific variability for most of the traits (Fig. 1), as maximum scores of $\mathrm{CV}$ across all species was larger than 0.29 , with the only exceptions of $\alpha$ and $\mathrm{F}_{\mathrm{v}} / \mathrm{F}_{\mathrm{m}}$ (Table 1). P. australis presented the lowest variable set of photophysiology traits except for $\mathrm{qP}(\mathrm{CV}<0.19)$, while nymphaeids had the most variable traits $(\alpha, \mathrm{qP}, \mathrm{Ca} / \mathrm{Cb}$ and $\mathrm{Chl} / \mathrm{Car}$ for $N$. alba; Chl-a, Chl-b and Car for N. lutea). L. hexapetala 


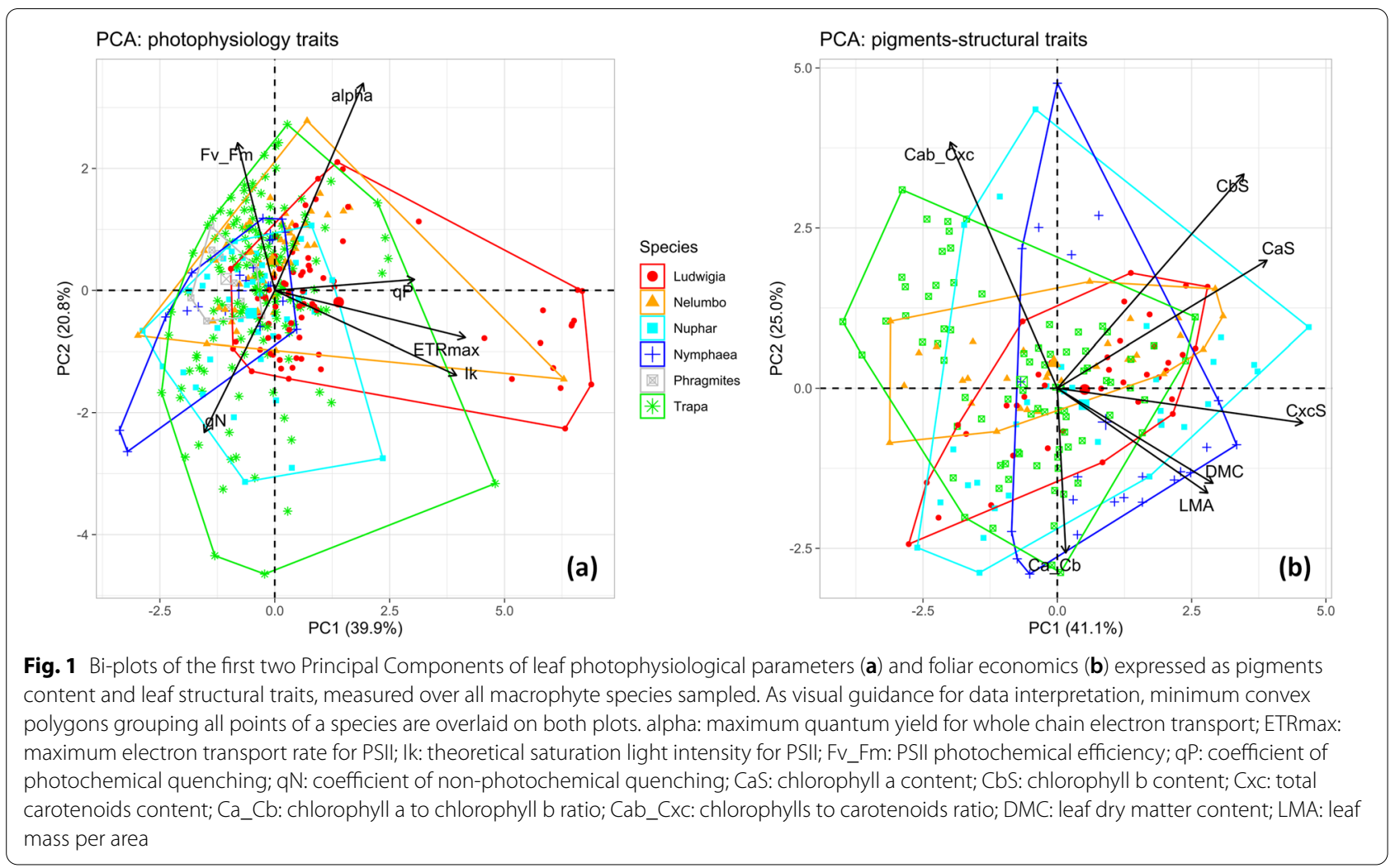

Table 1 Coefficient of variation (CV) of all leaf traits measured over macrophytes species sampled (highest scores across species for each trait are in bold, lowest in italic) at peak of growth conditions (July)

\begin{tabular}{|c|c|c|c|c|c|c|c|c|c|c|c|c|c|}
\hline \multirow[t]{2}{*}{ Species } & \multicolumn{6}{|c|}{ Photophysiology parameters } & \multicolumn{5}{|c|}{ Leaf pigments } & \multicolumn{2}{|c|}{ Leaf structure } \\
\hline & $a$ & $\mathrm{ETR}_{\max }$ & $I_{k}$ & $\mathrm{~F}_{\mathrm{v}} / \mathrm{F}_{\mathrm{m}}$ & $\mathrm{qN}$ & qP & Chl-a & Chl-b & Car & $\mathrm{Ca} / \mathrm{Cb}$ & Chl/Car & DMC & LMA \\
\hline L. hexapetala & 0.134 & 0.886 & 0.695 & 0.060 & 0.325 & 0.111 & 0.303 & 0.295 & 0.243 & 0.098 & 0.123 & 0.160 & 0.163 \\
\hline N. nucifera & 0.139 & 0.277 & 0.205 & 0.046 & 0.263 & 0.194 & 0.286 & 0.266 & 0.299 & 0.089 & 0.093 & 0.203 & 0.216 \\
\hline N. lutea & 0.149 & 0.279 & 0.255 & 0.064 & 0.133 & 0.242 & 0.313 & 0.434 & 0.307 & 0.186 & 0.302 & 0.086 & 0.171 \\
\hline N. alba & 0.202 & 0.396 & 0.244 & 0.029 & 0.183 & 0.378 & 0.190 & 0.368 & 0.293 & 0.293 & 0.363 & 0.136 & 0.217 \\
\hline P. australis & 0.074 & 0.172 & 0.187 & 0.044 & 0.072 & 0.156 & & & & & & & \\
\hline T. natans & 0.150 & 0.318 & 0.389 & 0.099 & 0.302 & 0.214 & 0.196 & 0.185 & 0.258 & 0.098 & 0.162 & 0.292 & 0.433 \\
\hline
\end{tabular}

showed very high plasticity in photophysiology parameters $\mathrm{ETR}_{\max }, \mathrm{I}_{\mathrm{k}}$, and $\mathrm{qN}(\mathrm{CV}>0.32)$, and $T$. natans scored highest intraspecific ranges of DMC and LMA $(\mathrm{CV}>0.29)$.

\section{Spectral indices as proxies for macrophyte leaf traits}

The correlations of every two-band combination NDSI correlations with investigated leaf traits measured on all macrophyte species sampled are highlighted in Figs. 2, 3 , 4 showing the optimal spectral proxies for each trait in the visible to near-infrared (VNIR) spectral range
(400-1000 nm) and in full spectral range (400-2500 nm), i.e. extending to shortwave infrared (SWIR) wavelengths.

The heterogeneity of measured samples not only in terms of species but also in terms of location (three study sites) and time of sampling (3 years, different months) which implies that our dataset includes a high variability in genetic features, seasonal cycles, stage of growths, plant conditions and environmental settings $(\mathrm{N}=324)$ overall resulted in relatively low correlation patterns $\left(\mathrm{R}_{\text {cal }}{ }^{2}<0.26\right)$ between leaf reflectance derived NDSI and measured photophysiological traits (Fig. 2). In particular, across all species, negligible correlations with any NDSI 


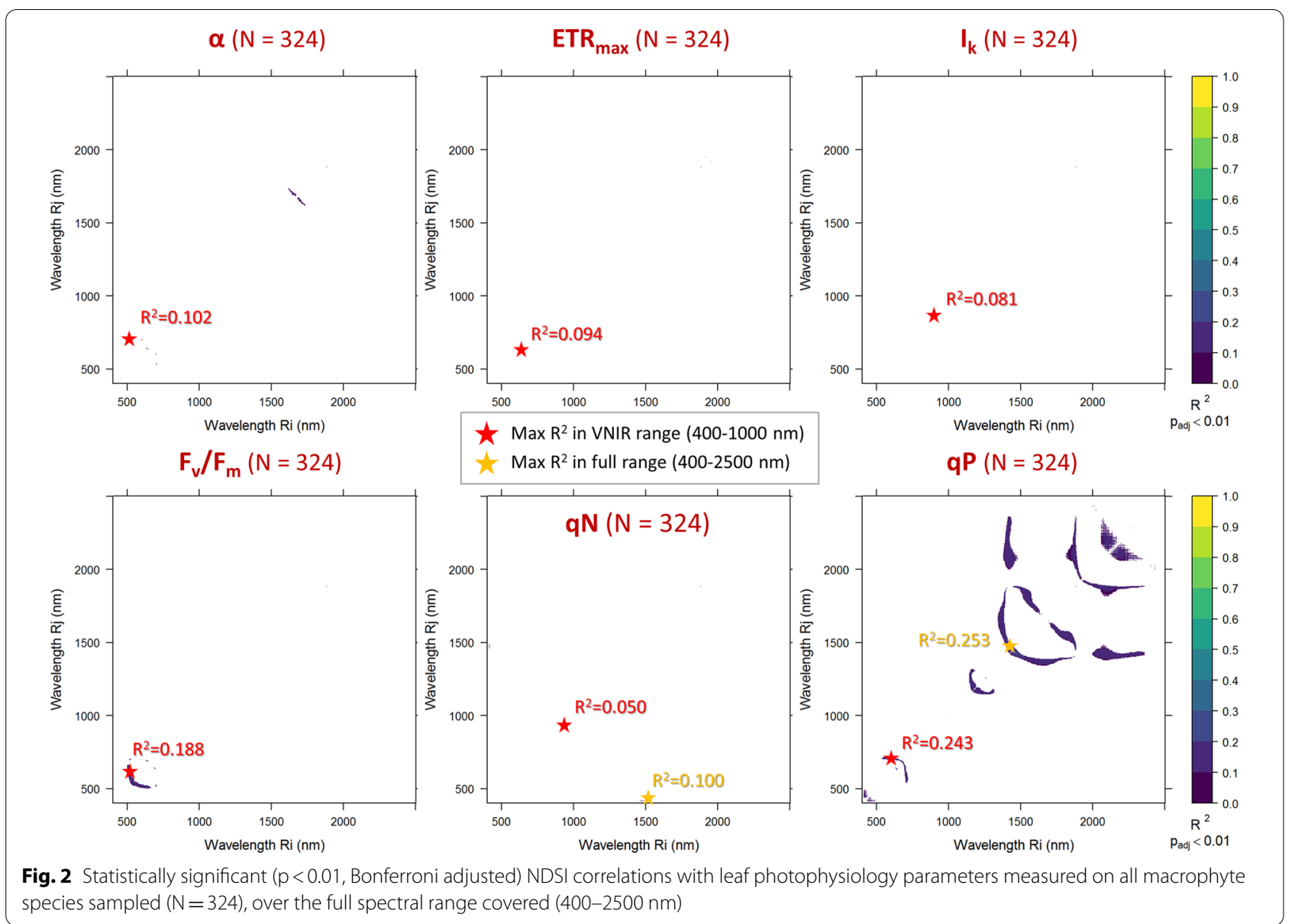

combinations were shown for $\alpha$ and $\mathrm{qN}$ (overall maximum $\mathrm{R}_{\text {cal }}{ }^{2}=0.10$, even if $\mathrm{p}_{\text {adj }}<0.01$ ), while results were not statistically significant $\left(\mathrm{p}_{\text {adj }} \geq 0.01\right)$ for $\mathrm{ETR}_{\max }$ and $\mathrm{I}_{\mathrm{k}}$. Slightly higher correlations, but still moderately weak, are shown for $\mathrm{F}_{\mathrm{v}} / \mathrm{F}_{\mathrm{m}}$ and $\mathrm{qP}$, with $\mathrm{R}_{\text {cal }}{ }^{2}$ peaking at 0.19 and $0.25\left(\mathrm{p}_{\mathrm{adj}}<0.01\right.$ ), respectively (Fig. 2). The optimal NDSI for $F_{v} / F_{m}$ combined reflectance in the range of green visible light $(524 \mathrm{~nm}, 581 \mathrm{~nm})$, while for qP the best spectral combinations lay in the SWIR range, roughly around $1400-1500 \mathrm{~nm}$.

Notwithstanding the abovementioned heterogeneity that biases the reflectance-photophysiology relations, correlations between pigments and NDSI computed from leaf reflectance across species are tangible, as peak $\mathrm{R}_{\text {cal }}{ }^{2}$ found was always higher than 0.3 (Fig. 3, $\mathrm{p}_{\text {adj }}<0.01$ ). In particular, NDSIs and Chl-a were found to be mutually correlated, particularly in the red-edge range (maximum $\mathrm{R}_{\text {cal }}{ }^{2}=0.43$ for $\mathrm{NDSI}_{775,740}, \mathrm{~N}=150$ ). As Chl-b is highly correlated with Chl-a in our dataset $(r=+0.80)$, optimal band combinations are found around the same range highlighted for Chl-a (795 nm, $740 \mathrm{~nm})$, yet with slightly weaker correlation (maximum $\mathrm{R}_{\text {cal }}^{2}=0.37, \mathrm{~N}=150$ ).
Among pigments, Car $(\mathrm{N}=150)$ showed the strongest correlations, peaking for NDSIs featuring band combinations in the SWIR range (maximum $R_{\text {cal }}{ }^{2}=0.57$ for $\mathrm{NDSI}_{1644,1720}$ ), while correlations decreased if the spectral range was limited to VNIR (maximum $\mathrm{R}_{\text {cal }}^{2}=0.37$ ). $\mathrm{Ca} /$ $\mathrm{Cb}$ ratio $(\mathrm{N}=151)$ showed the weakest correlations of all pigment traits, with a peak $R_{\text {cal }}{ }^{2}=0.31$ in the SWIR range (for $\left.\mathrm{NDSI}_{2181,2241}\right)$. Chl/Car ratio $(\mathrm{N}=151)$ is instead very well surrogated by NDSIs combining visible to SWIR reflectance (maximum $\mathrm{R}_{\text {cal }}{ }^{2}=0.60$ for $\mathrm{NDSI}_{611,1892}$ ); slightly lower correlations, yet still the highest among all pigments traits measured (maximum $\mathrm{R}_{\text {cal }}{ }^{2}=0.55$ ), were scored restricting the spectral range to VNIR range, where optimal NDSI for Chl/Car combined reflectance in $433 \mathrm{~nm}$ and $665 \mathrm{~nm}$, which indeed roughly correspond to absorption peaks of chlorophyll-a [66].

Relatively stronger correlations were scored between NDSIs derived and leaf structural traits measured, connected to leaf economics, DMC and LMA (Fig. 4). DMC $(\mathrm{N}=153)$ demonstrated a good sensitivity to leaf reflectance in the NIR to SWIR ranges $\left(\mathrm{p}_{\text {adj }}<0.01\right)$, with $R_{\text {cal }}{ }^{2}$ up to 0.47 (for $\operatorname{NDSI}_{1196,1308}$ ), and slightly weaker scores 

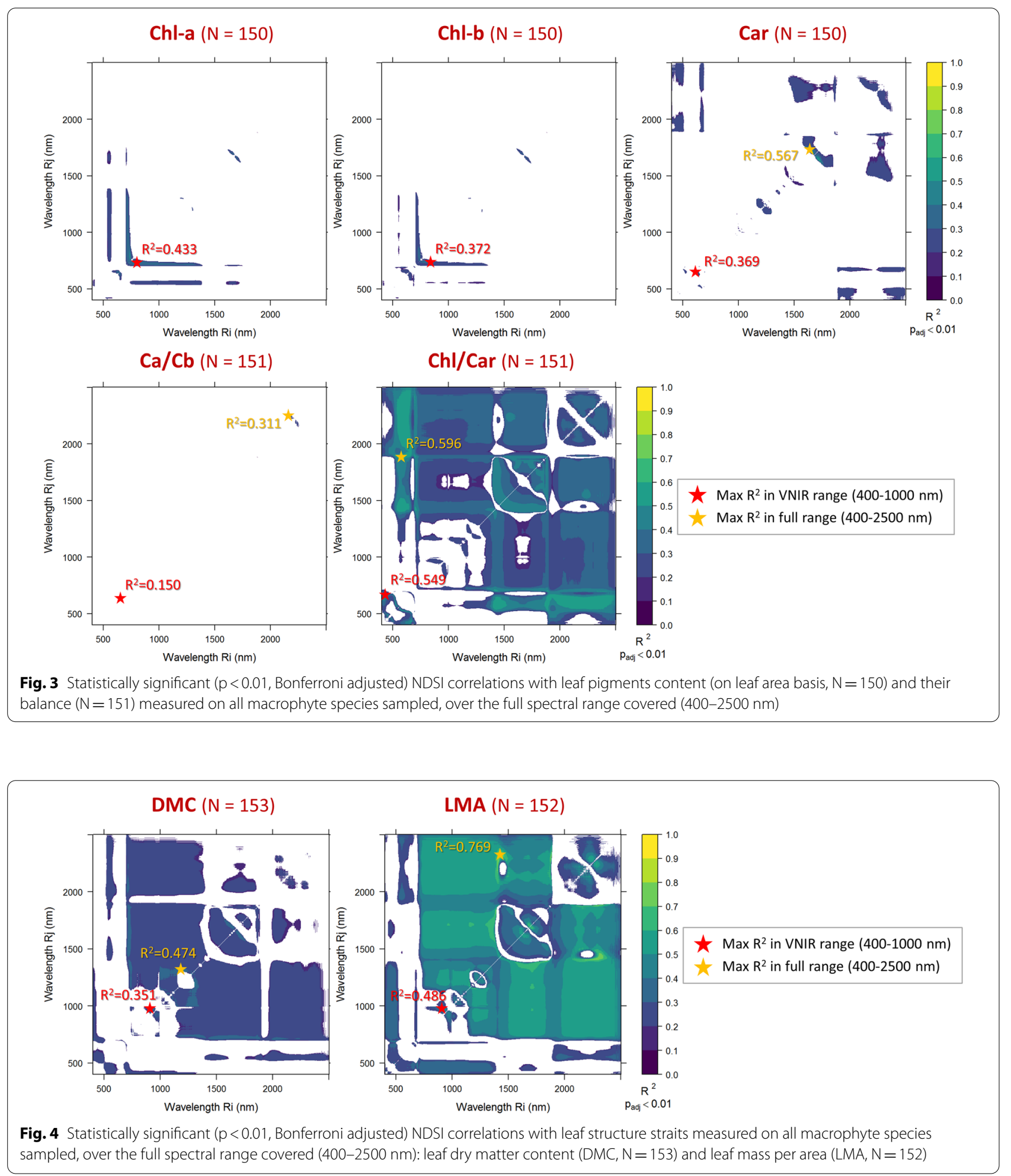

in the shorter VNIR wavelengths (maximum $\mathrm{R}_{\text {cal }}{ }^{2}=0.35$ for $\left.\mathrm{NDSI}_{929,941}\right)$. Among all leaf traits, LMA $(\mathrm{N}=152)$ scored the highest correlations with NDISs, with a large subset of band combinations showing $\mathrm{R}_{\mathrm{cal}}{ }^{2}>0.6$ in the
NIR to SWIR ranges, and a peak $\mathrm{R}_{\text {cal }}^{2}=0.77\left(\mathrm{p}_{\mathrm{adj}}<0.01\right)$ when two bands centred at 1415 and $2305 \mathrm{~nm}$ were used (Fig. 4). 


\section{Leaf reflectance-traits relations}

After having assessed mutual correlations of measured leaf traits, excluding the ones with $|r|>0.5$ (Additional file 1: Fig. S9), PLSR models were calibrated for traits scoring non-negligible correlations with best performing NDSIs presented in the previous section $\left(\mathrm{R}_{\mathrm{cal}}^{2}>0.15\right): \mathrm{F}_{\mathrm{v}} /$ $\mathrm{F}_{\mathrm{m}}$, qP, Chl-a, $\mathrm{Ca} / \mathrm{Cb}, \mathrm{Chl} / \mathrm{Car}, \mathrm{DMC}$, LMA.

The best fit PLSR models for $\mathrm{F}_{\mathrm{v}} / \mathrm{F}_{\mathrm{m}}$ and $\mathrm{qP}(\mathrm{N}=324)$ require 11 components, with RMSEP of 0.053 and 0.125 respectively (Additional file 1: Fig. S10). Matching between measured and predicted photophysiology traits was quite low for $\mathrm{F}_{\mathrm{v}} / \mathrm{F}_{\mathrm{m}}\left(\mathrm{R}_{\mathrm{CV}}{ }^{2}=0.21\right)$ and $\mathrm{qP}\left(\mathrm{R}_{\mathrm{CV}}{ }^{2}=0.33\right)$, even if estimation error seems to be reducing when extreme values-probably due to stress conditions non visibly detected when leaves were chosen for sampling-are excluded, i.e. for $\mathrm{F}_{\mathrm{v}} / \mathrm{F}_{\mathrm{m}}>0.65$, and $0.4<\mathrm{qP}<0.8$ (Fig. 5).

PLSR models based on leaf reflectance are quite effective in predicting macrophyte Chl-a content $(\mathrm{N}=150)$ and $\mathrm{Chl} / \mathrm{Car}$ ratio $(\mathrm{N}=151)$ across species, with best fit models requiring 11 and 13 components (Fig. 5, Additional file 1: Fig. S10) respectively, achieving RMSEP of $7.52 \mu \mathrm{g} \mathrm{cm}^{-2}\left(\mathrm{R}_{\mathrm{CV}}{ }^{2}=0.46, \mathrm{nRMSE}=16.6 \%\right)$ and 0.393 $\left(\mathrm{R}_{\mathrm{CV}}{ }^{2}=0.65\right.$, $\left.\mathrm{nRMSE}=12.7 \%\right)$. Figure 6 shows that VIP scores are high around 550-560 $\mathrm{nm}$ and 705-710 nm for Chl-a model and around 705-710 nm and $1400 \mathrm{~nm}$ for Chl/Car model. Conversely, modelling performance for $\mathrm{Ca} / \mathrm{Cb}$ is the lowest among traits considered here $\left(\mathrm{R}_{\mathrm{CV}}{ }^{2}=0.20\right)$, suggesting that spectral reflectance might not be a good proxy for this trait, at least for macrophyte species.

DMC $(\mathrm{N}=153)$ and LMA $(\mathrm{N}=152)$ are the leaf traits better surrogated by reflectance-based models (Fig. 5, Additional file 1: Fig. S10), with matching between measured and PLSR predicted scores up to $\mathrm{RMSEP}=0.026 \mathrm{~g} \mathrm{~g}^{-1} \quad(\mathrm{nRMSE}=12.1 \%)$ for DMC $\left(\mathrm{R}_{\mathrm{CV}}{ }^{2}=0.68\right.$, with 15 components $)$ and up to $\mathrm{RMSEP}=18.6 \mathrm{~g} \quad \mathrm{~m}^{-2} \quad(\mathrm{nRMSE}=11.7 \%)$ for LMA $\left(\mathrm{R}_{\mathrm{CV}}{ }^{2}=0.76\right.$, with 11 components $)$, across the whole range of measures in our dataset. VIP scores for DMC model are high around 400-410 nm and 1390-1400 nm, while for LMA model the wavelengths in VNIR range do not contribute much to prediction and peak VIP scores are found between 1400 and $1850 \mathrm{~nm}$, as well as between 2120 and $2300 \mathrm{~nm}$ (Fig. 6).

\section{Mapping spectral functional proxies from hyperspectral images}

The potential for application of the main findings described in previous sections was tested by producing spatial variability maps for selected spectral proxies of macrophyte traits deriving specific NDSIs from airborne hyperspectral data (APEX) collected over Lake Hídvégi and Mantua lakes system during different times of

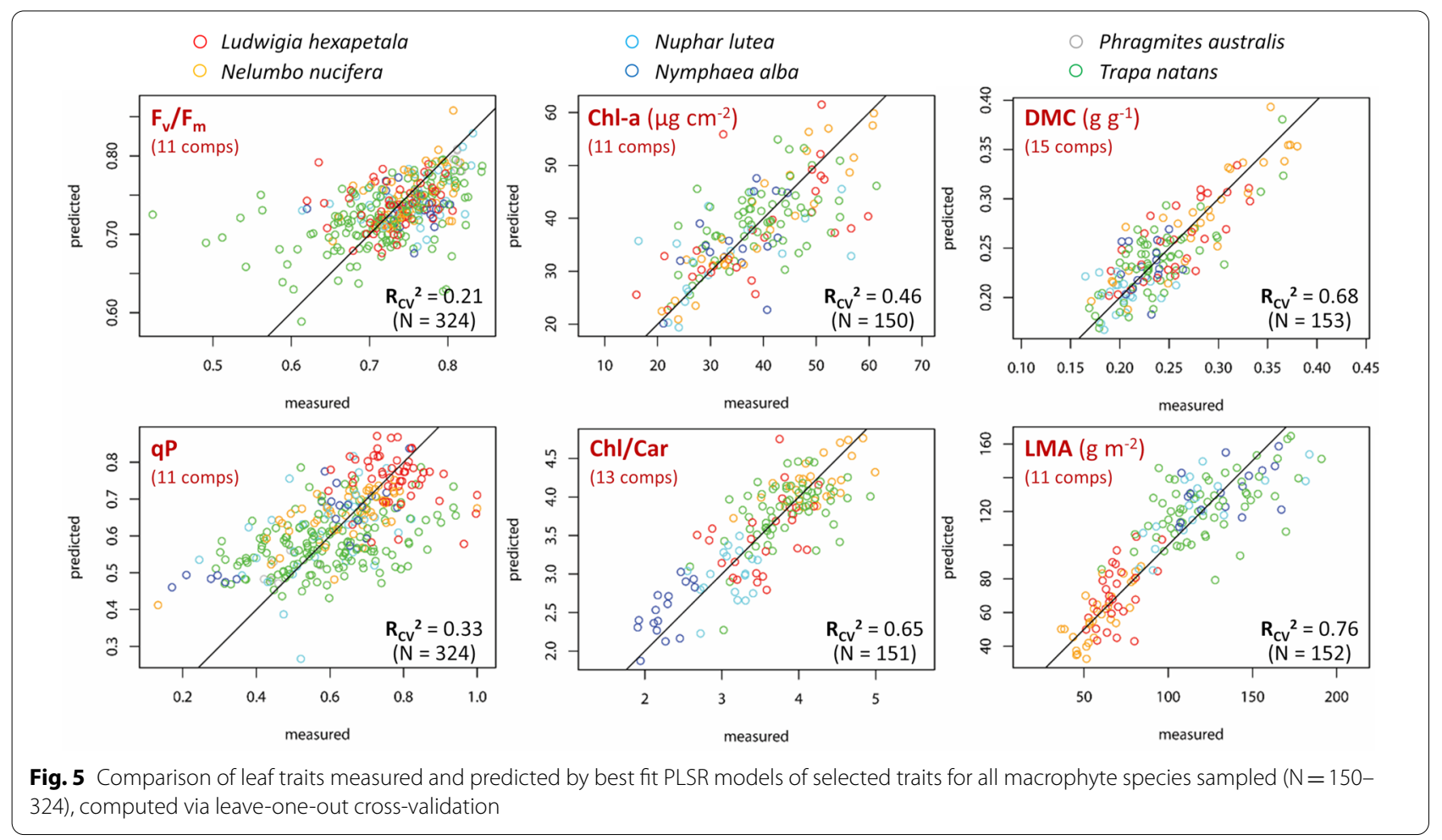



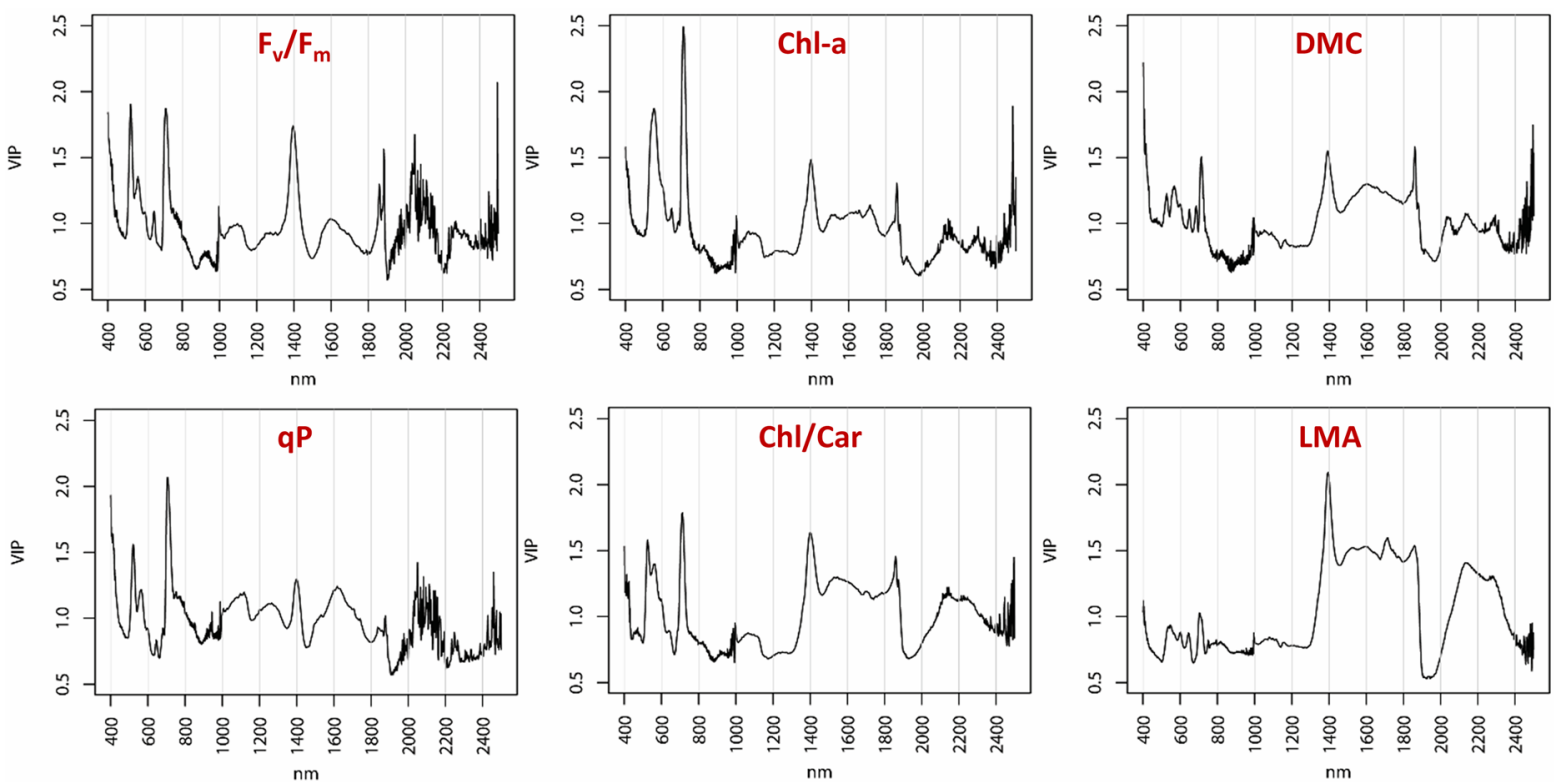

Fig. 6 Variable Importance of Projection (VIP) scores of PLSR models of selected leaf traits for all macrophyte species sampled, computed for each wavelength, over the full spectral range covered $(400-2500 \mathrm{~nm})$

summer in 2014. Maps are derived only for those spectral indices showing best matching with in situ measured data in the spectral range of APEX data (425-905 nm): i.e. $\mathrm{NDSI}_{775,740}$ as a proxy of Chl-a content $\left(\mathrm{R}_{\text {cal }}{ }^{2}=0.43\right)$, $\mathrm{NDSI}_{433,665}$ as a proxy of Chl/Car ratio $\left(\mathrm{R}_{\text {cal }}{ }^{2}=0.55\right)$, and NDSI $_{690,500}$ as a proxy of LMA $\left(\mathrm{R}_{\mathrm{cal}}{ }^{2}=0.44\right)$.

The application of NDSI proxies using RS data inevitably bring to more or less significant biases, reflecting into the reliability of plant functional traits retrieved, which are due to complex combinations of factors, including: vegetation fractional cover and mixture with canopy background, density and structure effects (e.g. leaf orientation), reflectance anisotropy, and atmospheric effects [32]. All the more so, spectral data measured from APEX airborne imager, with pixel size in this case of $5 \mathrm{~m}$, are inherently measuring the response of macrophyte beds at canopy scale, and application of proxies derived and assessed at leaf scale to some extent hampers the absolute matching of observation scales for spectral reflectance and plant traits. In deriving the maps of selected spectral proxies in Lake Hídvégi and Mantua lakes system (Fig. 7), we have partly tackled these distortion factors using reflectance normalization and masking our pixels with low canopy density $\left(\mathrm{LAI}<0.67 \mathrm{~m}^{2} \mathrm{~m}^{-2}\right)$. As a proof of concept of the usefulness of our findings to investigate spatial patterns of macrophyte functional diversity, maps shown in Fig. 7 are clearly capturing visible patterns of relative variability in macrophyte communities at withinsystem scale that can inform about specific features of macrophytes growing in Lake Hídvégi and Mantua lakes system.

\section{Discussion}

Due to their sedentary nature, plant survival depends on the possibility to acclimate or adapt to the given environmental conditions and biogeochemical processes of the area. The persistence of a species or a population is shaped by complex interactions of ecological and evolutionary attributes, and their changes during the growing season [74, 75]. Within the large variability typical of their habitat, macrophytes can establish and persist either by tolerating substantial environmental changes through their phenotypic plasticity or by shifting community composition when approaching a peripheral situation [76]. Macrophyte leaf trait data collected-covering different sites (three shallow lakes and wetlands in Europe), times (late May to late July), and seasons (3 years) - showed a high degree of heterogeneity, both within and among species sampled.

Some of the studied traits have evolutionary relevance: our data show that species with remarkable photochemical properties $-N$. nucifera with a higher maximum quantum yield of photosynthetic electron transport $(\alpha), L$. hexapetala with the highest maximum electron transport rate, saturation irradiance and photochemical quenching, and T. natans with the highest range of variability in quantum yield of PSII-correspond to those with a prominent presence in terms of stands area and spread 

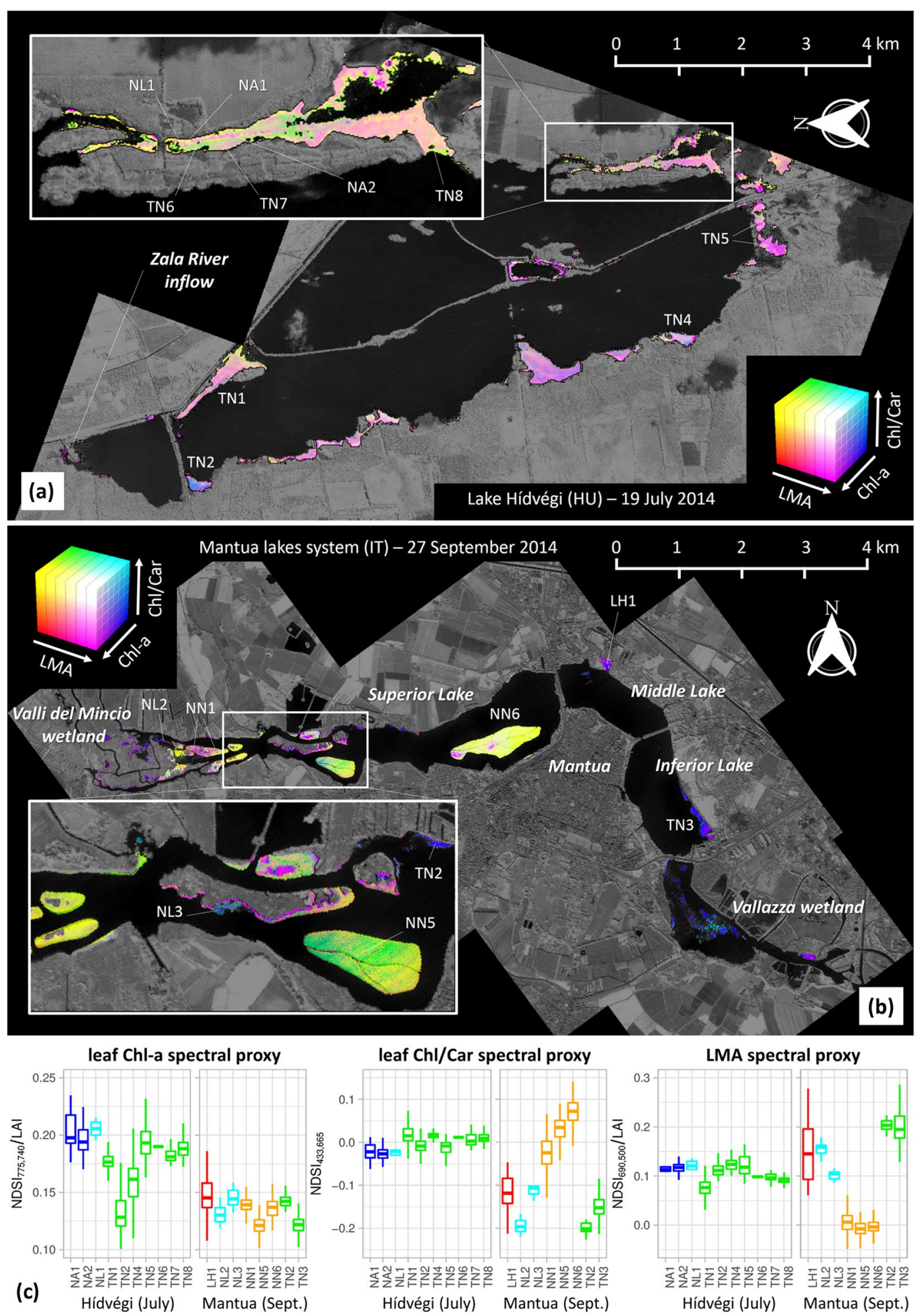

Fig. 7 Maps of spectral proxies (linked to selected traits from leaf spectroscopy) derived from airborne hyperspectral (APEX) data, showing RGB combinations of best two-band combined indices (NDSI) in the range covered by APEX data for Chl-a content (NDSI 740,775$),(\mathrm{Chl} / \mathrm{Car}$ ratio $\left(\mathrm{NDSI}_{433,665}\right.$ ), and LMA (NDSI 690,500$)$ : a macrophyte stands in Lake Hídvégi; b macrophyte stands in Mantua lakes system; c box plots of spectral proxies for individual mono-specific stands in both sites (indicated in panels a, b). LH: Ludwigia hexapetala; NN: Nelumbo nucifera; NL: Nuphar lutea; NA: Nymphaea alba; TA: Trapa natans 
in the study sites. Leaf pigments content and leaf structural traits rather showed ecological relevance, as truly floating-leaved species ( $N$. lutea and N. alba) had lower $\mathrm{Chl} / \mathrm{Car}$ ratio to make better use of underwater diffused light, while species with some leaves emerging above the water (L. hexapetala, N. nucifera) showed higher dry matter content and lower LMA.

Alien, invasive species tend to be photochemically more efficient (higher $\alpha, \mathrm{ETR}_{\max }$, or $\mathrm{I}_{\mathrm{k}}$ ) and to have lower LMA compared to native species growing in the same sites, which is in accordance with published findings on terrestrial plants $[77,78]$. Differently from what was found on a mass basis in previous works [60], foliar pigment content on an area basis did not separate alien and native plants, implying that interspecific differentiation in studied macrophytes is driven more by pigment proportions, and therefore by the ability of species to adapt to a given environment and maximise both light absorption and photoprotection $[79,80]$. These show the wide spectrum of macrophyte functional plasticity, but also hints at the individualistic responses of macrophytes to physical, chemical and anthropogenic characteristics of their environment.

Remote sensing spectroscopy is nearly the perfect tool to quantitatively assess the variability and specific trait distributions over large areas both within monospecific stands or mixed communities [46, 81], thus promoting functional studies focusing on inland water systems and connected ecotones and adding to literature that is considerably biased toward terrestrial ecosystems [82]. For this to work, a robust link between selected traits and spectral reflectance needs to be established starting from the fundamental leaf scale. Our results show that a suite of leaf functional traits, connected with light absorption and scattering mechanisms and representative of foliar economics trade-off, can be effectively modelled across floating and emergent macrophyte species based on leaf reflectance, thus complementing works performed in terrestrial ecosystems [32, 35, 39, 83], even under moderate to strong environmental heterogeneity, while photophysiology traits based on chlorophyll fluorescence measures could not be surrogated by leaf spectra with the same performance.

Best results were obtained via reflectance-based PLSR models for structural traits (leaf DMC and LMA), which constitute synthetic descriptors of leaf morphology, in particular the inner structure, mediating the effects of scattering mechanisms with water absorption [84]. These patterns generally confirm what has been documented from previous works on terrestrial plants at macro spectral ranges, i.e. in the SWIR [51, 52, 85-87], but with specific differences in optimal wavelengths to be used, possibly because of leaf structural peculiarities of aquatic plants [47]. Notably, in aquatic plants the accuracy of spectrally modelled LMA does not seem to depend on the magnitude of water content, deviating from the results of Riaño et al. [84], based on terrestrial species.

Complementing leaf structural traits in describing the trade-off at the core of the LES concept, leaf reflectance proved to be a good predictor of biochemistry-related traits in macrophytes, represented here by pigments pools and ratios. Chl-a content and $\mathrm{Chl} / \mathrm{Car}$ ratio were modelled with good reliability based on leaf spectroscopy and PLSR. Pigments are more directly related to spectral reflectance because of their primary function of interacting with light and their location within the leaf structure-i.e. in the first, adaxial strata aquatic plant leaves, as shown by Borsuk and Brodersen [88] for chlorophylls in the case of Eichornia crassipes (Mart.) Solms. Optimal wavelengths for Chl-a predictions were found in the rededge range (i.e. $700-800 \mathrm{~nm}$ ), similar to what extensively documented for terrestrial plants [52, 85, 87, 89], with VIP of PLSR model peaking around 705-710 nm. Best performing spectral combinations for $\mathrm{Ca} / \mathrm{Cb}$ ratio found around $2200 \mathrm{~nm}$ is possibly driven by the link between $\mathrm{Ca} / \mathrm{Cb}$ and $\mathrm{N}$ content [90], which we did not measure and it is known to show absorption features around $2180 \mathrm{~nm}$ from previous works [91, 92].

Contrary to what was highlighted for leaf economics traits, reflectance-based PLSR models for photophysiological parameters were found to be under-performing across the species sampled. Best results were scored for $\mathrm{F}_{\mathrm{v}} / \mathrm{F}_{\mathrm{m}} \quad\left(\mathrm{R}_{\mathrm{CV}}{ }^{2}=0.21\right)$, with optimal spectral range very similar to photochemical reflectance index (PRI) [93], and $\mathrm{qP}\left(\mathrm{R}_{\mathrm{CV}}{ }^{2}=0.33\right)$ roughly around $1400-1500 \mathrm{~nm}$. These figures contrast some recent findings of site-specific studies in crops and tree species [56, 94, 95], and suggest specificities in aquatic plants, possibly connected to high heterogeneity in studied macrophytes, that hampers the generality of photophysiology-reflectance link across species (Additional file 1: Figs. S4-S8). Our results demonstrate that spectral reflectance, relatively straightforward to measure quantity at ecosystem scale even in aquatic environments, can be used via normalized indices or PLSR modelling for reliably estimating specific macrophyte leaf traits (Chl-a, Chl/Car, DMC and LMA), strongly connected to variability expressed within the LES in terms of trade-offs between structural investment and photosynthetic efficiency [96, 97]. This complements previous works based on terrestrial plants (e.g. [32, 3842]) through new empirical data spanning over different species, seasonal, environmental conditions (sites) and phenological stages.

These findings provide the basis for using leaf spectra as a surrogate for high-throughput assessment of variability in macrophyte traits over scales and gradients and 
support the extension of the reflectance-based trait modelling to RS spectroscopic data for enhancing the level of detail of functional diversity analysis. In particular, the possibility of using spectral proxies for modelling macrophyte LMA opens intriguing perspectives for future research in aquatic species diversity and functioning and ecological applications of RS, aiming at investigating spatial and temporal gradients, helping to fill some of the gaps recently identified by Pan et al. [98]. The approach could be even extended to plant science in general, when paired with works already performed on terrestrial species [41]. Integrating high-resolution leaf reflectance spectroscopy with techniques based on Raman spectroscopy could potentially be highly profitable for further enhancing the study of processes and functioning of vegetation, including macrophytes [99].

Spatial-wise information derived from airborne hyperspectral data for spectral proxies connected to macrophyte traits can provide intuitive, realistic and detailed bio-visualisation of vegetation diversity and connected processes. Spatial patterns of variability in spectral proxies highlighted in Fig. 7 show differences at the site scale, due to both inter- and intra-species differentiation (e.g. T. natans in Lake Inferior, $N$. nucifera in Lake Superior within Mantua lakes system, Fig. 7b), as well as considerable variability at the community scale, indicating intraspecific trait plasticity (e.g. $\mathrm{NDSI}_{775,740}$ and $\mathrm{NDSI}_{690,500}$ of T. natans in Lake Hídvégi, as well as $\mathrm{NDSI}_{433,665}$ for $N$. nucifera in Mantua lakes system, Fig. 7c). Part of these differences are not only due to species composition but also to seasonal differences: APEX data collected over Lake Hídvégi in the middle of July represent macrophyte conditions at peak of growth, similar to most of the data we sampled in situ, while data for Mantua lakes system, acquired in late September, provide a static image of macrophyte communities in early to late senescence phase, depending on species, hence the high heterogeneity in $\mathrm{NDSI}_{433,665}$, linked to $\mathrm{Chl} / \mathrm{Car}$ ratio (Fig. 7c).

Indeed, the heterogeneity highlighted for macrophyte communities of Mantua lakes system and Lake Hídvégi could be hardly seen with punctual measurements of macrophyte traits, and yet it is captured in a systematic, synoptic and quantitative way by testing leaf reflectancetraits relations we found on remotely sensed imaging spectroscopy data, informing us on spatial and temporal functional variability. Although some interesting case studies in this respect have been recently documented (e.g. $[81,100,101])$, they were limited to one or few systems and few aquatic vegetation characteristics (functional types, phenology metrics) and wider applications are needed.

\section{Supplementary Information}

The online version contains supplementary material available at https://doi. org/10.1186/s13007-021-00816-4.

Additional file 1: Table S1. Summary of in situ samples collected for this study. Figure S1. Violin plots (with encompassed box plots) showing range and distribution of all leaf traits - photophysiological parameters, biochemistry (pigments) and leaf structure traits-measured over 6 macrophyte species ( $\mathrm{LH}=$ Ludwigia hexapetala; $\mathrm{NN}=$ Nelumbo nucifera; $\mathrm{NL}=$ Nuphar lutea; $\mathrm{NA}=$ Nymphaea alba; $\mathrm{PA}=$ Phragmites australis; $\mathrm{TN}=$ Trapa natans). Plots show significant differences $(\mathrm{p}<0.05)$ in pairwise comparison performed via Dunn's post-hoc test with Benjamini-Hochberg adjustment. Figure S2. Comparison of NDSI correlations $(p<0.01$, Bonferroni adjusted) with ETR $\mathrm{R}_{\max }$ for all samples $(\mathrm{N}=324)$, in the visible to near-infrared spectral range (400-1000 nm): computed using Pearson's $r$ and Spearman's $\rho$ on raw data (top row), or Pearson's $r$ based on raw and transformed $\left(1 / \sqrt{E T R_{\text {max }}}\right)$ data (bottom row). Figure S3. Comparison of NDSI correlations ( $p<0.01$, Bonferroni adjusted) with LMA for all samples $(\mathrm{N}=152)$, in the full spectral range $(400-2500 \mathrm{~nm})$ : computed using Pearson's $r$ and Spearman's $p$ on raw data (top row), or Pearson's $r$ based on raw and transformed $(\sqrt{L M A})$ data (bottom row). Figure S4. Statistically significant $(p<0.01$, Bonferroni adjusted) NDSI correlations with leaf photophysiology parameters measured on all macrophyte species sampled $(\mathrm{N}=324)$ in the visible to near-infrared spectral range $(400-1000 \mathrm{~nm})$. Figure S5. Statistically significant ( $p<0.01$, Bonferroni adjusted) NDSI correlations with leaf photophysiology parameters measured on Ludwigia hexapetala samples $(\mathrm{N}=53)$ in the visible to near-infrared spectral range (400-1000 nm). Figure S6. Statistically significant ( $p<0.01$, Bonferroni adjusted) NDSI correlations with leaf photophysiology parameters measured on Nelumbo nucifera samples $(\mathrm{N}=55)$ in the visible to near-infrared spectral range (400-1000 nm). Figure S7. Statistically significant $(p<0.01$, Bonferroni adjusted) NDSI correlations with leaf photophysiology parameters measured on Nuphar lutea and Nymphaea alba samples $(N=57)$ in the visible to near-infrared spectral range $(400-1000 \mathrm{~nm})$. Figure S8. Statistically significant ( $p<0.01$, Bonferroni adjusted) NDSI correlations with leaf photophysiology parameters measured on Trapa natans samples $(\mathrm{N}=154)$ in the visible to near-infrared spectral range $(400-1000 \mathrm{~nm})$. Figure S9. Correlation matrix of leaf traits measured over 6 species. Pairwise scatter plots are shown in the lower left half, histograms are shown on the diagonal, and the coefficient of correlation (Pearson's r) of each pair of traits is shown in the upper right half, including info about its significance level $\left({ }^{*} p<0.05,{ }^{* *} p<0.01,{ }^{* * *} p<0.001\right)$. Figure S10. Variation of root mean square error of prediction (RMSEP) with PLSR model components, computed against the full dataset (training or leave-oneout cross-validation) for selected leaf traits estimated from leaf spectral reflectance for all macrophyte species sampled. Figure S11. Comparison of distribution of selected spectral proxies (NDSI) derived from APEX data at Lake Hídvégi and Mantua lakes system for mono-specific stands and connected leaf traits measured in our dataset (at peak of growth conditions). Data points represent median scores and whiskers delimit the extremes of values observed. Linear regression lines and their coefficient of determination $\left(R^{2}\right)$ separating stands in senescence phase at the time of overflight over Mantua site (27 September 2014) are superimposed on the graphs. LH_yel: Ludwigia hexapetala (with signs of chlorotic conditions); NN_sen: Nelumbo nucifera (in early senescence phase); NL: Nuphar lutea; NA: Nymphaea alba; TN: Trapa natans; TN_sen: Trapa natans (around senescence conditions).

\section{Acknowledgements}

The authors thank the Parco del Mincio authority and voluntary ecological guards for the support given during fieldwork in the Mantua lakes system. Many thanks to Mauro Musanti (CNR-IREA) and Attila Kovács (BLI, Centre for Ecological Research) for their help during fieldwork on Lake Hídvégi.

\section{Authors' contributions}

PV, VRT designed the study, collected the data, performed the analysis, and drafted the manuscript. RB, MP supported the collection of data and interpretation of results. All authors read and approved the final manuscript. 


\section{Funding}

This work was supported by the agreement on scientific cooperation between the Hungarian Academy of Sciences and the Consiglio Nazionale delle Ricerche (MacroSense project), and by the Hungarian National Research, Development and Innovation Office, NKFIH [Grant No. 135832]. Part of the work was carried out in the context of the EU FP7 programme through the INFORM project [Grant No. 730066].

\section{Availability of data and materials}

The datasets generated and/or analysed during the current study will be made available in public repositories upon publication: leaf traits data will be deposited in Dryad (datadryad.org); leaf reflectance spectra will be deposited also in EcoSIS (ecosis.org).

\section{Declarations}

Ethics approval and consent to participate

Not applicable.

\section{Consent for publication}

Not applicable.

\section{Competing interests}

The authors declare that they have no competing interests.

\section{Author details}

${ }^{1}$ Institute for Electromagnetic Sensing of the Environment, National Research Council of Italy (CNR-IREA), Milan, Italy. ${ }^{2}$ Department of Chemistry, Life Sciences and Environmental Sustainability, University of Parma, Parma, Italy.

${ }^{3}$ Balaton Limnological Research Institute, Tihany, Hungary.

Received: 1 September 2021 Accepted: 30 October 2021

Published online: 10 November 2021

\section{References}

1. Mitsch WJ, Bernal B, Nahlik AM, Mander Ü, Zhang L, Anderson CJ, Jørgensen SE, Brix H. Wetlands, carbon, and climate change. Landsc Ecol. 2013;28:583-97.

2. Tranvik LJ, Downing JA, Cotner JB, Loiselle SA, Striegl RG, Ballatore TJ, Dillon P, Finlay K, Fortino K, Knoll LB, et al. Lakes and reservoirs as regulators of carbon cycling and climate. Limnol Oceanogr. 2009:54:2298-314.

3. Bridgham SD, Megonigal JP, Keller JK, Bliss NB, Trettin C. The carbon balance of North American wetlands. Wetlands. 2006:26:889-916.

4. Keddy PA, Fraser LH, Solomeshch Al, Junk WJ, Campbell DR, Arroyo MTK, Alho CJR. Wet and wonderful: the world's largest wetlands are conservation priorities. Bioscience. 2009;59:39-51.

5. Wetzel RG. Land-water interfaces: metabolic and limnological regulators. SIL Proc. 1990;24:6-24.

6. Spence DHN. The zonation of plants in freshwater lakes. In: Macfadyen A, Ford ED, editors. Advances in ecological research. Cambridge: Academic Press; 1982. p. 37-125.

7. Bornette G, Puijalon S. Response of aquatic plants to abiotic factors: a review. Aquat Sci. 2011;73:1-14.

8. Vivian-Smith G. Microtopographic heterogeneity and floristic diversity in experimental wetland communities. J Ecol. 1997;85:71.

9. Franklin P, Dunbar M, Whitehead P. Flow controls on lowland river macrophytes: a review. Sci Total Environ. 2008;400:369-78.

10. Schindler DE, Scheuerell MD. Habitat coupling in lake ecosystems. Oikos. 2002;98:177-89.

11. Jeppesen E, Søndergaard M, Søndergaard M, Christoffersen K, editors. The structuring role of submerged macrophytes in lakes. New York: Springer; 1998. p. 425.

12. Wang W, Fraser JD, Chen J. Distribution and long-term population trends of wintering waterbirds in Poyang Lake, China. Wetlands. 2019:39:125-35
13. Bolpagni R. Towards global dominance of invasive alien plants in freshwater ecosystems: the dawn of the Exocene? Hydrobiologia. 2021. https://doi.org/10.1007/s10750-020-04490-w.

14. Chuine I. Why does phenology drive species distribution? Philos Trans $R$ Soc B Biol Sci. 2010;365:3149-60.

15. De Kroon H, Huber H, Stuefer JF, Van Groenendael JM. A modular concept of phenotypic plasticity in plants: research review. New Phytol. 2005; 166:73-82.

16. Elzinga JA, Atlan A, Biere A, Gigord L, Weis AE, Bernasconi G. Time after time: flowering phenology and biotic interactions. Trends Ecol Evol. 2007:22:432-9.

17. Tóth VR, Szabó K. Morphometric structural analysis of Phragmites australis stands in Lake Balaton. Ann Limnol Int J Limnol. 2012;48:241-51.

18. Tóth VR, Vári Á. Impact of habitat environment on Potamogeton perfoliatus L. morphology and its within-plant variability in Lake Balaton. Ann Limnol Int J Limnol. 2013:49:149-55.

19. Tóth VR, Palmer SCJ. Acclimation of Potamogeton perfoliatus L. to periphyton accumulation-induced spectral changes in irradiance. Hydrobiologia. 2016;766:293-304.

20. Butler EE, Datta A, Flores-Moreno H, Chen M, Wythers KR, Fazayeli F, Banerjee A, Atkin OK, Kattge J, Amiaud B, et al. Mapping local and global variability in plant trait distributions. Proc Natl Acad Sci. 2017;114:E10937-46.

21. Hu Y-K, Pan X, Liu G-F, Li W-B, Dai W-H, Tang S-L, Zhang Y-L, Xiao T, Chen $L-Y$, Xiong W, et al. Novel evidence for within-species leaf economics spectrum at multiple spatial scales. Front Plant Sci. 2015;6:901.

22. Messier J, McGill BJ, Lechowicz MJ. How do traits vary across ecological scales? A case for trait-based ecology: how do traits vary across ecological scales? Ecol Lett. 2010;13:838-48.

23. Albert $\mathrm{CH}$, Thuiller W, Yoccoz NG, Soudant A, Boucher F, Saccone P, Lavorel S. Intraspecific functional variability: extent, structure and sources of variation. J Ecol. 2010;98:604-13.

24. Bloomfield KJ, Cernusak LA, Eamus D, Ellsworth DS, Prentice IC, Wright IJ, Boer MM, Bradford MG, Cale P, Cleverly J, et al. A continental-scale assessment of variability in leaf traits: within species, across sites and between seasons. Funct Ecol. 2018;32:1492-506.

25. Osnas JLD, Katabuchi M, Kitajima K, Wright SJ, Reich PB, Van Bael SA, Kraft NJB, Samaniego MJ, Pacala SW, Lichstein JW. Divergent drivers of leaf trait variation within species, among species, and among functional groups. Proc Natl Acad Sci. 2018;115:5480-5.

26. Wright IJ, Reich PB, Westoby M, Ackerly DD, Baruch Z, Bongers F, Cavender-Bares J, Chapin T, Cornelissen JHC, Diemer M, et al. The worldwide leaf economics spectrum. Nature. 2004;428:821-7.

27. Dahlin KM, Asner GP, Field CB. Environmental and community controls on plant canopy chemistry in a Mediterranean-type ecosystem. Proc Natl Acad Sci. 2013;110:6895-900.

28. Kraft NJB, Valencia R, Ackerly DD. Functional traits and niche-based tree community assembly in an amazonian forest. Science. 2008;322:580-2.

29. Kumordzi BB, Wardle DA, Freschet GT. Plant assemblages do not respond homogenously to local variation in environmental conditions: functional responses differ with species identity and abundance. J Veg Sci. 2015;26:32-45.

30. Sandel B, Low R. Intraspecific trait variation, functional turnover and trait differences among native and exotic grasses along a precipitation gradient. J Veg Sci. 2019;30:633-43.

31. Funk JL, Larson JE, Ames GM, Butterfield BJ, Cavender-Bares J, Firn J, ..., Wright J. Revisiting the $\mathrm{H}$ oly $\mathrm{G}$ rail: using plant functional traits to understand ecological processes. Biol Rev. 2017;92(2):1156-73.

32. Asner GP, Martin RE, Anderson CB, Knapp DE. Quantifying forest canopy traits: imaging spectroscopy versus field survey. Remote Sens Environ. 2015;158:15-27.

33. Dalla Vecchia A, Villa P, Bolpagni R. Functional traits in macrophyte studies: current trends and future research agenda. Aquat Bot. 2020:167:103290.

34. Gamon JA, Somers B, Malenovský Z, Middleton EM, Rascher U, Schaepman ME. Assessing vegetation function with imaging spectroscopy. Surv Geophys. 2019;40:489-513.

35. Homolová L, Malenovský Z, Clevers JGPW, García-Santos G, Schaepman ME. Review of optical-based remote sensing for plant trait mapping. Ecol Complex. 2013;15:1-16. 
36. Verrelst J, Camps-Valls G, Muñoz-Marí J, Rivera JP, Veroustraete F, Clevers JGPW, Moreno J. Optical remote sensing and the retrieval of terrestrial vegetation bio-geophysical properties - a review. ISPRS J Photogramm Remote Sens. 2015;108:273-90.

37. Wang R, Gamon JA. Remote sensing of terrestrial plant biodiversity. Remote Sens Environ. 2019;231:111218.

38. Asner G, Martin R. Spectral and chemical analysis of tropical forests: scaling from leaf to canopy levels. Remote Sens Environ. 2008:112:3958-70.

39. Kattenborn T, Fassnacht FE, Schmidtlein S. Differentiating plant functional types using reflectance: which traits make the difference? Remote Sens Ecol Conserv. 2019;5:5-19.

40. Schweiger AK, Schütz M, Risch AC, Kneubühler M, Haller R, Schaepman ME. How to predict plant functional types using imaging spectroscopy: linking vegetation community traits, plant functional types and spectral response. Methods Ecol Evol. 2017:8:86-95.

41. Serbin SP, Wu J, Ely KS, Kruger EL, Townsend PA, Meng R, Wolfe BT, Chlus A, Wang Z, Rogers A. From the Arctic to the tropics: multibiome prediction of leaf mass per area using leaf reflectance. New Phytol. 2019:224:1557-68.

42. Singh A, Serbin SP, McNeil BE, Kingdon CC, Townsend PA. Imaging spectroscopy algorithms for mapping canopy foliar chemical and morphological traits and their uncertainties. Ecol Appl. 2015;25:2180-97.

43. Van Cleemput E, Roberts DA, Honnay O, Somers B. A novel procedure for measuring functional traits of herbaceous species through field spectroscopy. Methods Ecol Evol. 2019;10:1332-8.

44. Feilhauer H, Schmid T, Faude U, Sánchez-Carrillo S, Cirujano S. Are remotely sensed traits suitable for ecological analysis? A case study of long-term drought effects on leaf mass per area of wetland vegetation. Ecol Ind. 2018;88:232-40.

45. Stratoulias D, Balzter H, Zlinszky A, Tóth VR. Assessment of ecophysiology of lake shore reed vegetation based on chlorophyll fluorescence, field spectroscopy and hyperspectral airborne imagery. Remote Sens Environ. 2015;157:72-84

46. Villa P, Pinardi M, Tóth VR, Hunter PD, Bolpagni R, Bresciani M. Remote sensing of macrophyte morphological traits: implications for the management of shallow lakes. J Limnol. 2017;76(s1):109-26.

47. Klančnik K, Gaberščik A. Leaf spectral signatures differ in plant species colonizing habitats along a hydrological gradient. J Plant Ecol. 2016:9:442-50.

48. Pierce S, Brusa G, Sartori M, Cerabolini BEL. Combined use of leaf size and economics traits allows direct comparison of hydrophyte and terrestrial herbaceous adaptive strategies. Ann Bot. 2012;109:1047-53.

49. Díaz S, Kattge J, Cornelissen JH, Wright IJ, Lavorel S, Dray S, ..., Gorné LD. (2016). The global spectrum of plant form and function. Nature. 2016;529(7585):167-71.

50. Jacquemoud S, Verhoef W, Baret F, Bacour C, Zarco-Tejada PJ, Asner GP, François C, Ustin SL. PROSPECT+SAIL models: a review of use for vegetation characterization. Remote Sens Environ. 2009;113:S56-66.

51. Ali AM, Darvishzadeh R, Skidmore AK, van Duren I. Specific leaf area estimation from leaf and canopy reflectance through optimization and validation of vegetation indices. Agric For Meteorol. 2017;236:162-74.

52. Le Maire G, Francois C, Soudani K, Berveiller D, Pontailler J, Breda N, Genet H, Davi H, Dufrene E. Calibration and validation of hyperspectral indices for the estimation of broadleaved forest leaf chlorophyll content, leaf mass per area, leaf area index and leaf canopy biomass. Remote Sens Environ. 2008;112:3846-64.

53. Yao X, Zhu Y, Tian Y, Feng W, Cao W. Exploring hyperspectral bands and estimation indices for leaf nitrogen accumulation in wheat. Int J Appl Earth Obs Geoinf. 2010;12:89-100

54. Ely KS, Burnett AC, Lieberman-Cribbin W, Serbin SP, Rogers A. Spectroscopy can predict key leaf traits associated with source-sink balance and carbon-nitrogen status. J Exp Bot. 2019;70:1789-99.

55. Feilhauer H, Asner GP, Martin RE, Schmidtlein S. Brightness-normalized Partial Least Squares Regression for hyperspectral data. J Quant Spectrosc Radiat Transf. 2010;111:1947-57.

56. Fu P, Meacham-Hensold K, Guan K, Wu J, Bernacchi C. Estimating photosynthetic traits from reflectance spectra: a synthesis of spectral indices, numerical inversion, and partial least square regression. Plant Cell Environ. 2020;43:1241-58.
57. Korponai J, Braun M, Buczkó K, Gyulai I, Forró L, Nédli J, Papp I. Transition from shallow lake to a wetland: a multi-proxy case study in Zalavári Pond, Lake Balaton, Hungary. Hydrobiologia. 2010;641:225-44.

58. Dinka M, Ágoston-Szabó E, Urbanc-Berčič O, Germ M, Šraj-Kržič N, Gaberščik A. Reed stand conditions at selected wetlands in Slovenia and Hungary. In: Vymazal J, editor. Wastewater treatment, plant dynamics and management in constructed and natural wetlands. Dordrecht: Springer; 2008. p. 1-12.

59. Pinardi M, Bartoli M, Longhi D, Viaroli P. Net autotrophy in a fluvial lake: the relative role of phytoplankton and floating-leaved macrophytes. Aquat Sci. 2011;73:389-403.

60. Tóth VR, Villa P, Pinardi M, Bresciani M. Aspects of invasiveness of ludwigia and nelumbo in shallow temperate fluvial lakes. Front Plant Sci. 2019;10:647.

61. Villa P, Bresciani M, Bolpagni R, Pinardi M, Giardino C. A rule-based approach for mapping macrophyte communities using multi-temporal aquatic vegetation indices. Remote Sens Environ. 2015;171:218-33.

62. Genty B, Briantais J-M, Baker NR. The relationship between the quantum yield of photosynthetic electron transport and quenching of chlorophyll fluorescence. Biochim Biophys Acta (BBA) Gen Subj. 1989;990:87-92.

63. Wellburn AR. The spectral determination of chlorophylls $a$ and $b$, as well as total carotenoids, using various solvents with spectrophotometers of different resolution. J Plant Physiol. 1994;144(3):307-13.

64. Blackburn GA. Hyperspectral remote sensing of plant pigments. J Exp Bot. 2006;58:855-67.

65. Glenn E, Huete A, Nagler P, Nelson S. Relationship between remotelysensed vegetation indices, canopy attributes and plant physiological processes: what vegetation indices can and cannot tell us about the landscape. Sensors. 2008;8:2136-60.

66. Ustin SL, Gitelson AA, Jacquemoud S, Schaepman M, Asner GP, Gamon JA, Zarco-Tejada P. Retrieval of foliar information about plant pigment systems from high resolution spectroscopy. Remote Sens Environ. 2009;113:S67-77.

67. Thenkabail PS, Smith RB, De Pauw E. Hyperspectral vegetation indices and their relationships with agricultural crop characteristics. Remote Sens Environ. 2000;71:158-82.

68. Geladi P, Kowalski BR. Partial least-squares regression: a tutorial. Anal Chim Acta. 1986;185:1-17

69. Mevik B-H, Wehrens R. The pls package: principal component and partial least squares regression in R. J Stat Softw. 2007;18(2):1-23.

70. R Core Team. R: A language and environment for statistical computing. R Foundation for Statistical Computing, Vienna, Austria; 2021. https:// www.R-project.org/. Accessed 1 Sept 2021.

71. Wold S, Sjöström M, Eriksson L. PLS-regression: a basic tool of chemometrics. Chemom Intell Lab Syst. 2001;58:109-30.

72. Schaepman ME, Jehle M, Hueni A, D'Odorico P, Damm A, Weyermann J, Schneider FD, Laurent V, Popp C, Seidel FC, et al. Advanced radiometry measurements and Earth science applications with the Airborne Prism Experiment (APEX). Remote Sens Environ. 2015;158:207-19.

73. de Haan JF, Hovenier JW, Kokke JMM, van Stokkom HTC. Removal of atmospheric influences on satellite-borne imagery: a radiative transfer approach. Remote Sens Environ. 1991;37:1-21.

74. Kinnison MT, Hairston NG. Eco-evolutionary conservation biology: contemporary evolution and the dynamics of persistence. Funct Ecol. 2007;21:444-54.

75. Parmesan C. Ecological and evolutionary responses to recent climate change. Annu Rev Ecol Evol Syst. 2006;37:637-69.

76. Søndergaard M, Johansson LS, Lauridsen TL, Jørgensen TB, Liboriussen $L$, Jeppesen E. Submerged macrophytes as indicators of the ecological quality of lakes. Freshw Biol. 2010;55:893-908.

77. Leishman MR, Haslehurst T, Ares A, Baruch Z. Leaf trait relationships of native and invasive plants: community- and global-scale comparisons. New Phytol. 2007;176:635-43.

78. Reich PB, Ellsworth DS, Walters MB, Vose JM, Gresham C, Volin JC, Bowman WD. Generality of leaf trait relationships: a test across six biomes. Ecology. 1999:80:1955-69.

79. Grimshaw HJ, Havens K, Sharfstein B, Steinman A, Anson D, East T, Maki RP, Rodusky A, Jin K-R. The effects of shading on morphometric and meristic characteristics of Wild Celery, Vallisneria americana MICHX. 
transplants from Lake Okeechobee, Florida. Fundam Appl Limnol. 2002;155:65-81.

80. Hussner A, Hoelken HP, Jahns P. Low light acclimated submerged freshwater plants show a pronounced sensitivity to increasing irradiances. Aquat Bot. 2010;93:17-24.

81. Bolpagni R, Bresciani M, Laini A, Pinardi M, Matta E, Ampe EM, Giardino C, Viaroli P, Bartoli M. Remote sensing of phytoplankton-macrophyte coexistence in shallow hypereutrophic fluvial lakes. Hydrobiologia. 2014;737:67-76

82. Gustafsson C, Norkko A. Quantifying the importance of functional traits for primary production in aquatic plant communities. J Ecol. 2019;107:154-66.

83. Van Cleemput E, Vanierschot L, Fernández-Castilla B, Honnay O, Somers B. The functional characterization of grass- and shrubland ecosystems using hyperspectral remote sensing: trends, accuracy and moderating variables. Remote Sens Environ. 2018;209:747-63.

84. Riaño D, Vaughan P, Chuvieco E, Zarco-Tejada PJ, Ustin SL. Estimation of fuel moisture content by inversion of radiative transfer models to simulate equivalent water thickness and dry matter content: analysis at leaf and canopy level. IEEE Trans Geosci Remote Sens. 2005:43:819-26.

85. Féret J-B, François C, Gitelson A, Asner GP, Barry KM, Panigada C, Richardson $A D$, Jacquemoud $S$. Optimizing spectral indices and chemometric analysis of leaf chemical properties using radiative transfer modeling. Remote Sens Environ. 2011;115:2742-50.

86. Féret J-B, le Maire G, Jay S, Berveiller D, Bendoula R, Hmimina G, Cheraiet $A$, Oliveira JC, Ponzoni FJ, Solanki $\mathrm{T}$, et al. Estimating leaf mass per area and equivalent water thickness based on leaf optical properties: potential and limitations of physical modeling and machine learning. Remote Sens Environ. 2019;231:110959.

87. Wang Q, Li P. Hyperspectral indices for estimating leaf biochemical properties in temperate deciduous forests: comparison of simulated and measured reflectance data sets. Ecol Ind. 2012;14:56-65.

88. Borsuk AM, Brodersen CR. The spatial distribution of chlorophyll in leaves. Plant Physiol. 2019;180:1406-17.

89. Gitelson AA, Gritz Y, Merzlyak MN. Relationships between leaf chlorophyll content and spectral reflectance and algorithms for non-destructive chlorophyll assessment in higher plant leaves. J Plant Physiol. 2003;160:271-82.

90. Kitajima K, Hogan KP. Increases of chlorophyll a/b ratios during acclimation of tropical woody seedlings to nitrogen limitation and high light. Plant Cell Environ. 2003;26:857-65.
91. Kokaly RF. Investigating a physical basis for spectroscopic estimates of leaf nitrogen concentration. Remote Sens Environ. 2001;75:153-61.

92. Li D, Wang X, Zheng H, Zhou K, Yao X, Tian Y, Zhu Y, Cao W, Cheng T. Estimation of area- and mass-based leaf nitrogen contents of wheat and rice crops from water-removed spectra using continuous wavelet analysis. Plant Methods. 2018;14:76.

93. Harris A, Gamon JA, Pastorello GZ, Wong CYS. Retrieval of the photochemical reflectance index for assessing xanthophyll cycle activity: a comparison of near-surface optical sensors. Biogeosciences. 2014;11:6277-92.

94. Dechant B, Cuntz M, Vohland M, Schulz E, Doktor D. Estimation of photosynthesis traits from leaf reflectance spectra: correlation to nitrogen content as the dominant mechanism. Remote Sens Environ. 2017;196:279-92.

95. Maimaitiyiming M, Ghulam A, Bozzolo A, Wilkins JL, Kwasniewski MT. Early detection of plant physiological responses to different levels of water stress using reflectance spectroscopy. Remote Sens. 2017;9:745.

96. Onoda Y, Wright IJ, Evans JR, Hikosaka K, Kitajima K, Niinemets Ü, Poorter H, Tosens T, Westoby M. Physiological and structural tradeoffs underlying the leaf economics spectrum. New Phytol. 2017;214:1447-63.

97. Poorter H, Niinemets Ü, Poorter L, Wright IJ, Villar R. Causes and consequences of variation in leaf mass per area (LMA): a meta-analysis. New Phytol. 2009;182:565-88.

98. Pan Y, Cieraad E, van Bodegom PM. Are ecophysiological adaptive traits decoupled from leaf economics traits in wetlands? Funct Ecol. 2019;33:1202-10.

99. Payne WZ, Kurouski D. Raman spectroscopy enables phenotyping and assessment of nutrition values of plants: a review. Plant Methods. 2021;17:78.

100. Tóth VR. Monitoring spatial variability and temporal dynamics of phragmites using unmanned aerial vehicles. Front Plant Sci. 2018;9:728.

101. Villa P, Pinardi M, Bolpagni R, Gillier J-M, Zinke P, Nedelcuț F, Bresciani $M$. Assessing macrophyte seasonal dynamics using dense time series of medium resolution satellite data. Remote Sens Environ. 2018;216:230-44.

\section{Publisher's Note}

Springer Nature remains neutral with regard to jurisdictional claims in published maps and institutional affiliations.
Ready to submit your research? Choose BMC and benefit from:

- fast, convenient online submission

- thorough peer review by experienced researchers in your field

- rapid publication on acceptance

- support for research data, including large and complex data types

- gold Open Access which fosters wider collaboration and increased citations

- maximum visibility for your research: over 100M website views per year

At BMC, research is always in progress.

Learn more biomedcentral.com/submissions 